\title{
Mechanisms of action of FdUMP[10]: Metabolite activation and thymidylate synthase inhibition
}

\author{
I.V. BIJNSDORP ${ }^{1}$, E.M. COMIJN ${ }^{1}$, J.M.PADRON ${ }^{1}$, W.H. GMEINER ${ }^{2}$ and G.J.PETERS ${ }^{1}$ \\ ${ }^{1}$ Department of Medical Oncology, VU University Medical Center, PO Box 7057, 1007 MB Amsterdam, \\ The Netherlands; ${ }^{2}$ Department of Biochemistry, Wake Forest University School of Medicine, \\ Medical Center Boulevard, Winston-Salem, NC 27157, USA
}

Received February 26, 2007; Accepted April 5, 2007

\begin{abstract}
FdUMP[10] is a multimer of FdUMP, a suicide inhibitor of thymidylate synthase (TS), and was designed to bypass resistance to 5 -fluorouracil (5FU). The aim of the study was to compare the effect of FdUMP[10] with 5FU and 5-fluoro-2-deoxyuridine (FUdR) in their efficacy to inhibit their target TS in resistant cells. Therefore cell lines FM3A/0, FM3A/TK- (deficient in thymidine kinase) and FM3A/TS (deficient in thymidylate synthase) were used to determine TK dependency and specificity for TS inhibition. FdUMP[10] inhibited cell growth with greater potency than 5FU and FdUMP. Direct folate-based inhibitors Raltitrexed, GW1843U89 and Pemetrexed were also evaluated using these cell lines. In TK-deficient cells these folate-based inhibitors had greater potency than the fluoropyrimidines (FPs). Surprisingly, Pemetrexed even inhibited cell growth in TS-deficient cells. Incubation with nucleotidase and phosphatase inhibitors resulted in a reduction of cytotoxicity of FdUMP[10], indicating that the drug can be degraded outside the cells. In the TS in situ inhibition assay (TSIA) $24 \mathrm{~h}$ exposure of FM3A cells to $0.5 \mu \mathrm{M}$ FdUMP and $0.05 \mu \mathrm{M}$ FdUMP[10] decreased TSIA to 7 and $1 \%$ of control. Inhibition of nucleotidase and phosphatase activities reduced the effect of FdUMP[10], while the inhibitory effect was lower in cells lacking TK. FdUMP[10] can enter the cells intact, but also to some extent after dephosphorylation. In conclusion, FdUMP[10] can bypass resistance to FUdR by direct inhibition of TS.
\end{abstract}

\section{Introduction}

The pro-drugs 5-fluorouracil (5FU) and 5-fluoro-2'-deoxyuridine (FUdR) are widely used as standard treatment of

Correspondence to: Professor G.J. Peters, Department of Medical Oncology, VU University Medical Center, PO Box 7057, 1007 MB Amsterdam, The Netherlands

E-mail: gj.peters@vumc.nl

Key words: FdUMP[10], 5-fluorouracil, thymidylate synthase, thymidine kinase advanced colorectal carcinoma (1), however the response rates have been suboptimal with an objective tumor response of $10-20 \%$. Meta-analysis attempts have shown that the efficacy of $5 \mathrm{FU}$ can be improved by either schedule alteration or biochemical modulation with leucovorin (LV) (2). However, severe toxicities are a clinical problem that needs to be diminished. Drug resistance is also a limitation in the treatment of patients with these drugs (3).

One important mechanism of action of 5FU and FUdR is inhibition of thymidylate synthase (TS) via the metabolite FdUMP. TS is an essential enzyme for de novo synthesis of thymidylate (dTMP), a precursor for DNA synthesis. FdUMP is a potent suicide inhibitor of TS, but either cellular uptake or intracellular activation to FdUMP may limit the effect of 5FU (2). Therefore a multimer of FdUMP, FdUMP[10] was synthesized $(4,5)$, which acts as a pro-drug of FdUMP (Fig. 1).

FdUMP[10] itself is $100 \% 10$-mer and is relatively stable in cell culture medium, with more than $50 \%$ present as multimers of at least 6 nucleotides after $48 \mathrm{~h}$ at $37^{\circ} \mathrm{C}$ (6). After cellular uptake, FdUMP may be released intracellularly to inhibit TS. FdUMP[10] was 400 times more cytotoxic than 5 FU towards H630 cells (4). In the 5FU-resistant TSoverexpressing variant H630-10, resistance to FdUMP[10] was reduced 10 -fold compared to 100 -fold for $5 \mathrm{FU}$ (5). These data indicate that FdUMP[10] might exert its action not only by direct inhibition of TS, but also indirectly via one of its metabolites.

Antifolates are the oldest class of antimetabolites and have been in clinical use for many years (7). New TS inhibitors have been developed that are direct inhibitors of TS and direct inhibitors of one or both of the two folate-dependent enzymes of de novo purine synthesis (8-10). After preclinical evaluation, many have moved to clinical trials. Several antifolates can inhibit more than one pathway in folate metabolism. These inhibitors include GW1843U89, Raltitrexed (ZD1694, Tomudex), Thymitaq (Nolatrexed) and Alimta (pemetrexed, LY231514). GW1843U89 (11) and Thymitaq (12) are in earlier phases of clinical development (10). Raltitrexed and Alimta have shown potency in phase II/III clinical trials for several tumor types, including mesothelioma and colorectal cancer (13-16). Raltitrexed is currently approved only in Europe for the treatment of colon cancer, but Pemetrexed is registered for treatment of both mesothelioma and non-small cell lung cancer (NSCLC). 


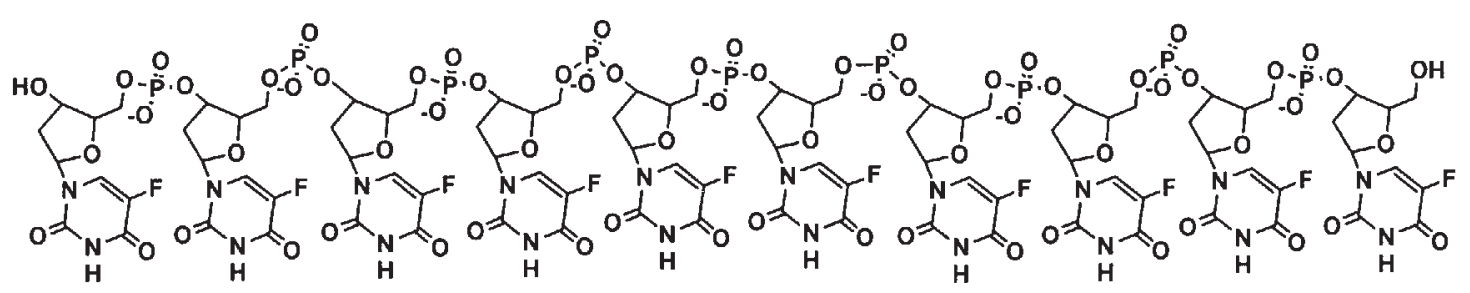

\section{FdUMP[10]}

Figure 1. Chemical structure of FdUMP[10].

In this study, we have determined the role of TS inhibition in the action of FdUMP[10] using the TS in situ assay (TSIA), which evaluates intracellular TS inhibition. Cell lines deficient in either thymidine kinase (TK) or TS and inhibitors of FdUMP degradation were used to study the importance of these pathways. The effects were also compared to direct, folate-based inhibition of TS.

\section{Materials and methods}

Cell culture. FM3A/0 cells are derived from mouse mammary carcinoma. FM3A/TK- cells are deficient in the key enzyme TK, which confers resistance to FUdR (17). FM3A/TS- cells are deficient in TS, and were cultured with $20 \mu \mathrm{M}$ thymidine. The cell lines were cultured in RPMI supplemented with $10 \%$ heat inactivated FCS and $20 \mathrm{mM}$ HEPES buffer. Cells were grown in suspension in a humidified atmosphere containing $5 \% \mathrm{CO}_{2}$ at $37^{\circ} \mathrm{C}$.

Chemicals. FdUMP[10] was synthesized as described earlier (4-6). The precursors of FdUMP[10], 5FU, FdUMP, 5-fluoro2'-deoxyuridine (FUdR) were obtained from Sigma (The Netherlands). The antifolates used were generously provided by the following persons/institutions: Alimta (Eli Lilly, Indianapolis, USA), GW1843U89 (Dr R. Ferone, Glaxo/ Welcome), AG337 (Nolatrexed, Thymitaq; Dr R.C. Jackson, Agouron/Pfizer), and ZD1694 (Raltitrexed, Tomudex; Dr F.T. Boyle, AstraZeneca Pharmaceuticals/Aston, UK). These antifolates have different transport mechanisms and various polyglutamylation and accumulation patterns which are all important for drug sensitivity (7). Tritiated deoxycytidine ([5$\left.{ }^{3} \mathrm{H}\right]$-deoxycytidine), tritiated FdUMP $\left({ }^{3} \mathrm{H}-\mathrm{FdUMP}\right)$ and tritiated dUMP $\left[5-{ }^{3} \mathrm{H}\right]$-dUMP were obtained from Moravek Biochemicals (CA, USA).

Drug cytotoxicity. Drug cytotoxicity was determined using the MTT-assay [3-(4,5-dimethylthiazol-2-yl)-2,5-diphenyltetrazolium bromide) (Sigma Chemicals, St. Louis, MO, USA) as described previously (18). Briefly, 10,000 cells/well were seeded in triplicate in 96-well flat bottom plates. After $24 \mathrm{~h}$, increasing concentrations of drugs were added. After $72 \mathrm{~h}$ of continuous exposure to the drugs, $10 \mu 1 \mathrm{MTT}(5 \mathrm{mg} / \mathrm{ml})$ was added to each well for $3 \mathrm{~h}$. Subsequently, the formed crystals were dissolved by adding $0.004 \mathrm{~N} \mathrm{HCl}$ in isopropanol. Optical density was measured at $540 \mathrm{~nm}$. In order to determine the potential breakdown of the drugs by extracellular nucleotidases or aspecific phosphatases, cells were incubated with
$2.5 \mathrm{mM} \alpha, \beta$-methylene-ADP (AOPCP) or $15 \mathrm{mM}$ 2-glycerolphosphate (2GP), respectively. These concentrations were previously shown to prevent nucleotidase or phosphatase mediated breakdown of fluorinated pyrimidine nucleotides (19).

TS in situ activity. For the TSIA assay, tritiated deoxycytidine was used, which, after cellular uptake, was converted to tritiated dCMP, subsequently to tritiated dUMP, and by TS to dTMP, releasing tritiated water (20). TSIA was evaluated in control cells and after a 4-h drug exposure, a 4-h exposure followed by incubation in drug-free medium (DFM), and a 24-h exposure. Potential breakdown by extracellular nucleotidases or aspecific phosphatases was inhibited by addition of $2.5 \mathrm{mM}$ AOPCP or $15 \mathrm{mM} 2 \mathrm{GP}$, respectively.

TS activity and FdUMP binding assay. Activity of TS was determined at the approximate half-saturating $(1 \mu \mathrm{M})$ and saturating substrate concentration $(10 \mu \mathrm{M}$ dUMP) in which the $\left[5-{ }^{3} \mathrm{H}\right]$-dUMP is converted to dTMP (21). The FdUMP binding assay was performed as described previously $(22,23)$. In brief, $50 \mu 1$ enzyme suspension from supernatants, $50 \mu 1$ $6.4 \mathrm{mM}$ N5,N10-methylene tetrahydrofolate $\left(\mathrm{CH}_{2}\right.$-THF), $15 \mu 1$ $570 \mathrm{nM}\left[6-{ }^{3} \mathrm{H}\right]-\mathrm{FdUMP}$ in a total volume of $250 \mu \mathrm{l}$ in Tris- $\mathrm{HCl}$ buffer (200 mM, pH 7.4) were used. The reaction was started by adding the enzyme and was incubated at $37^{\circ} \mathrm{C}$ for $1 \mathrm{~h}$ and stopped by adding $500 \mu 110 \%$ activated charcoal. After centrifugation, radioactivity was estimated by liquid scintillation counting of $250 \mu 1$ supernatant.

\section{Results}

Drug cytotoxicty. The effect of FdUMP[10] on cell growth was compared with the compounds FdUMP, 5FU and FUdR. As shown in Table I, FM3A/0 and FM3A/TK- cells were both sensitive to $5 \mathrm{FU}$ treatment, while the activity of 5FU was potentiated by LV. FM3A/0 cells were more sensitive to FUdR and FdUMP than to 5FU treatment. FM3A/TK- cells were resistant to both FUdR and FdUMP treatment. Interestingly, FdUMP [10] strongly inhibited cell growth in both FM3A cell lines, with an $\mathrm{IC}_{50}$ value as low as $0.022-3 \mathrm{nM}$ and a much lower resistance factor than FUdR and FdUMP. To determine whether the drugs are cleaved in- or outside the cells, FM3A/0 and FM3A/TK- cells were incubated with nucleotidase and phosphatase inhibitors. FdUMP and FdUMP[10] cytotoxicity decreased 6- to 8-fold after incubation with these inhibitors, indicating that the drug can be degraded outside the cells. Surprisingly, 5FU cytotoxicity also decreased 2- to 4-fold. 
Table I. Sensitivity of FM3A cells to 5FU, FdUMP, FdUMP[10] in comparison to antifolates.

\begin{tabular}{|c|c|c|c|c|c|}
\hline Drug & FM3A/0 & FM3A/TK' & RF & FM3A/TS- & RF \\
\hline $5 \mathrm{FU}$ & $310 \pm 25$ & $220 \pm 42$ & $0.7^{\mathrm{a}}$ & $230 \pm 130$ & 0.7 \\
\hline $5 \mathrm{FU}+\mathrm{LV}$ & $160 \pm 90$ & $87 \pm 30$ & 0.5 & $2600 \pm 520$ & 16 \\
\hline FUdR & $5.0 \pm 1.3$ & $2467 \pm 23.3$ & $493^{a}$ & nd & \\
\hline FdUMP & $2.8 \pm 0.46$ & $2667 \pm 32.9$ & $945^{\mathrm{b}}$ & nd & \\
\hline FdUMP[10] & $0.022 \pm 0.005$ & $3.0 \pm 0.7$ & $136^{\mathrm{a}}$ & nd & \\
\hline Raltitrexed & $16 \pm 4$ & $5 \pm 2$ & $0.3^{\mathrm{a}}$ & $>100000$ & $>1000^{b}$ \\
\hline Nolatrexed & $1280 \pm 400$ & $496 \pm 230$ & $0.4^{\mathrm{a}}$ & $>100000$ & $>100^{\mathrm{b}}$ \\
\hline GW1843U89 & $164 \pm 82$ & $72 \pm 16$ & 0.4 & $>10000$ & $>100^{\mathrm{b}}$ \\
\hline Pemetrexed & $36 \pm 8$ & $24 \pm 6$ & $0.7^{\mathrm{a}}$ & $348 \pm 110$ & $10^{\mathrm{b}}$ \\
\hline
\end{tabular}

Values represent $\mathrm{IC}_{50}(\mathrm{nM})$. FM3A cells were exposed to the drugs for $72 \mathrm{~h}$. Values are means $\pm \mathrm{SEM}$ of 3 separate experiments. RF represents the resistance factor, which represents the dependency on TK or TS for the drug to be active. RF is calculated by dividing the $\mathrm{IC}_{50} \mathrm{value} \mathrm{ff}$ the drug in $\mathrm{FM}_{3 \mathrm{~A}} / \mathrm{TK}^{-}$or $\mathrm{FM} 3 \mathrm{~A} / \mathrm{TS}^{-}$through the $\mathrm{IC}_{50}$ value of that drug in $\mathrm{FM} 3 \mathrm{~A} / 0$ cells. nd, not done; ${ }^{\mathrm{a}} \mathrm{p} \leq 0.05,{ }^{\mathrm{b}} \mathrm{p}<0.005$ ).

Table II. TS levels in untreated FM3A/0 and FM3A/TK- cells using different assays.

\begin{tabular}{|c|c|c|}
\hline & FM3A/0 & FM3A/TK- \\
\hline $\begin{array}{l}\text { FdUMP binding } \\
\text { (fmol/mg protein) }\end{array}$ & $1129 \pm 142.6$ & $1060 \pm 63.5$ \\
\hline \multicolumn{3}{|l|}{ Catalytic activity } \\
\hline $\begin{array}{l}1 \mu \mathrm{M} \mathrm{dUMP} \\
(\mathrm{pmol} / \mathrm{h} / \mathrm{mg} \text { protein) }\end{array}$ & $1630 \pm 252.3$ & $1729 \pm 113.7$ \\
\hline $\begin{array}{l}10 \mu \mathrm{M} \text { dUMP } \\
(\mathrm{pmol} / \mathrm{h} / \mathrm{mg} \text { protein) }\end{array}$ & $3163 \pm 458.4$ & $3238 \pm 230.4$ \\
\hline TS in intact cells & & \\
\hline $\begin{array}{l}\text { TS in situ activity } \\
\left(\mathrm{pmol} / \mathrm{h} / 10^{6} \text { cells }\right)\end{array}$ & $52 \pm 5.2$ & $86 \pm 1.7$ \\
\hline
\end{tabular}

TS activity in untreated FM3A/0 and FM3A/TK- cells was determined with the FdUMP binding assay and the TS catalytic assay, at substrate concentrations at half-saturating $(1 \mu \mathrm{M}$, which is around the $\mathrm{Km}$ value) and at saturating conditions $(10 \mu \mathrm{M})$. The activity of TS in situ was determined for untreated cells with the TS in situ assay. Values are means \pm SEM from 3 separate experiments.

Next, we determined the effect of various folate-based TS inhibitors on cell growth in the FM3A cell lines (Table I). Both FM3A/0 and TK- cells were sensitive to these TS inhibitors. Growth of the TK-deficient cells was inhibited about 2- to 3-fold better than in wild-type cells. To confirm if the observed cytotoxicity was specifically related to TS inhibition, FM3A cells, deficient in TS (FM3A/TS-), were also tested with these drugs (Table I). This cell line is highly resistant to treatment with these TS inhibitors, with an $\mathrm{IC}_{50}$ greater than $100 \mu \mathrm{M}$. Pemetrexed showed a smaller increase in $\mathrm{IC}_{50}$ value in these cells.
Table III. TS inhibition of FdUMP[10], FdUMP, 5FU and FUdR in FM3A/0 cells.

\begin{tabular}{lrrr}
\hline & & $4 \mathrm{~h}+20 \mathrm{~h}$ \\
Drug & $4 \mathrm{~h}$ & $\mathrm{DFM}$ & $24 \mathrm{~h}$ \\
\hline Controls & 100 & 100 & 100 \\
$1000 \mathrm{nM} 5 \mathrm{FU}$ & $47 \pm 8$ & $70 \pm 14$ & $20 \pm 4$ \\
$5 \mathrm{nM} \mathrm{FUdR}$ & $0 \pm 0$ & $55 \pm 2$ & $0 \pm 0$ \\
$500 \mathrm{nM}$ FdUMP & $19 \pm 4$ & $61 \pm 9$ & $7 \pm 2$ \\
500 nM FdUMP + inhibitors & $11 \pm 3$ & $81 \pm 10$ & $26 \pm 5$ \\
50 nM FdUMP[10] & $7 \pm 2$ & $69 \pm 7$ & $1 \pm 1$ \\
50 nM FdUMP[10] + inhibitors & $35 \pm 7$ & $96 \pm 16$ & $56 \pm 9$ \\
\hline
\end{tabular}

Values are \% of untreated control cells, controls were set at $100 \%$ for each separate experiment. Intact FM3A cells were exposed to the drugs for 4 and 24 or $4 \mathrm{~h}$ followed by $20 \mathrm{~h}$ drug-free medium (DFM). TSIA was measured by addition of tritiated deoxycytidine for the last hour of the assay. Inhibitors consist of a mixture of $15 \mathrm{mM}$ $2 \mathrm{GP}$ and $2.5 \mathrm{mM}$ AOPCP. Values are means \pm SEM of 3-5 separate experiments.

TS in situ activity. Both FM3A/0 and FM3A/TK- have similar levels of intracellular TS, measured using different assays (Table II). In both cell lines, TS in situ activity was strongly inhibited by both the nucleotides FdUMP and FdUMP[10], while $5 \mathrm{nM}$ FUdR completely inhibited TS in situ activity. In contrast, 5FU only partially inhibited in situ TS activity (Table III). This inhibition was partially retained when incubated in drug-free medium. In FM3A/TK- cells, FdUMP, FdUMP[10] and FUdR were inactive (TSIA >82\%), while $1 \mu \mathrm{M} 5 \mathrm{FU}$ itself reduced TSIA to $60 \pm 3 \%$, but only after $24 \mathrm{~h}$ exposure. These data indicated that the action of FdUMP[10] was partially dependent on degradation to FUdR. In order to determine whether this was an extra- or intracellular process, we incubated cells with AOPCP and 2GP, which significantly 
protected cells from the inhibitory effects of FdUMP[10], indicating that the nucleotide is indeed broken down. However, there was still a substantial in situ TS inhibition when the drugs remained present, indicating a direct effect of FdUMP[10] on TS activity. Surprisingly, FdUMP itself was a potent inhibitor of TS activity in situ, which even seemed to be increased by the inhibitors after $4 \mathrm{~h}$, but not after culture in drug-free medium or after $24 \mathrm{~h}$. It is also remarkable that after $24 \mathrm{~h}$ continuous exposure with nucleotide breakdown inhibitors the TS in situ activity is less inhibited.

\section{Discussion}

FdUMP[10] is an active compound which either acts as a pro-drug for FUdR, or after its uptake can inhibit TS directly. Both actions are favorable, since resistance to fluoropyrimidines can be due to either a decreased uptake, a decreased activation or less efficient inhibition of TS (3,24-26). FdUMP[10] can potentially bypass each mechanism and its favorable therapeutic effect can be due to a combination of these effects. FdUMP[10] has a higher activity than 5FU and FUdR in the NCI 60-cell line screening panel, and has a higher activity in cells overexpressing TS (4). Also in our study FdUMP[10] showed a higher activity than both 5FU and FUdR. However, resistance mechanisms depending on activation of either 5FU or FUdR can not always completely be bypassed (4) since TK-deficient cells showed a reduced sensitivity to FdUMP[10]. However, FM3A/TK- cells were more sensitive to FdUMP[10] than to FUdR or FdUMP. The resistance factor for FdUMP was comparable to that of FUdR, indicating equal levels of dependency to TK for cytotoxic action. Since nucleotidase and phosphatase inhibitors reduced the cytotoxic activity, it is expected that FdUMP[10] may be degraded outside the cell to some extent.

Although FdUMP[10] may have two pathways by which it is active, it was not clear how much each pathway will contribute to each effect. In this study we focused on the relation between the initial cellular effect, TS inhibition, and the final effect, growth inhibition. Both untreated FM3A/0 and FM3A/ $\mathrm{TK}^{-}$cells had equal levels of TS concentration. Therefore, the difference in sensitivity to FdUMP[10] can not be explained by differences in TS activities in these cell lines.

The reduced folate leucovorin ( $\mathrm{LV}$, folinic acid), is usually given in combination with $5 \mathrm{FU}$ and enhances TS inhibition mediated by the 5FU metabolite, FdUMP (2). A difference in sensitivity was observed between wild-type cells and TK and TS deficient cells to 5-FU/LV treatment. FM3A/TK- cells were more sensitive when $5 \mathrm{FU}$ was combined with $\mathrm{LV}$, which may indicate that the mechanism of action in these cells changes to cell death due to TS inhibition, in contrast to the mechanism of action of 5FU only, which may also be due to incorporation into RNA (2). FM3A/TS- cells were less sensitive to $5 \mathrm{FU}$ when $\mathrm{LV}$ was added, which also indicated that enhancement of cellular response is predominantly due to formation of a complex with TS and CH2THF in the wildtype cells. Without addition of $\mathrm{LV}$ a different mechanism is of more importance in the induction of cell death.

Other antifolates, including Raltitrexed, Nolatrexed, GW1843U89 and Pemetrexed were also evaluated. As expected, FM3A/TS- cells were insensitive to antifolate treatment. However, these cells were relatively sensitive to Pemetrexed. This can be explained based on previous studies showing that Pemetrexed has other targets additional to TS inhibition. Most likely this is due to inhibition of GARFT (27) and dihydrofolate reductase (DHFR) (28).

Although the extent of degradation was not quantified, these data provide clear evidence that degradation of FdUMP[10] to FUdR can be important, since inhibition of FdUMP[10] degradation to a deoxynucleoside markedly decreased the TS inhibition. This effect may be different between various tumor types. In the presence of the nucleotide breakdown inhibitors there was still a substantial TS inhibition, indicating a direct effect of FdUMP[10]. The decreased TS inhibition after $24 \mathrm{~h}$ with these nucleotide breakdown inhibitors may be an indirect effect, because TS inhibition will lead to dUMP accumulation (29), which will be broken down by the cells. In patients this leads to deoxyuridine accumulation (30). In the presence of the breakdown inhibitors, dUMP might not be degraded and will therefore accumulate in the cells. This will subsequently reduce TS inhibition, by competition with FdUMP (31-33). Alternatively exposure of cells to 5FU leads to an induction of TS (34), which may reduce the effect as well.

Since many tumor cells contain a relatively high nucleotidase and/or phosphatase levels (19), its activation can be rather tumor specific. This will lead to a tumor-specific uptake and activation of FdUMP[10], which at least partially explains its better therapeutic effect compared to 5FU in several in vivo model systems. Future studies should attempt to characterize the contribution of each pathway in in vivo models.

\section{Acknowledgements}

This study supported in part by NIH-NCI CA102532 (WHG) and NIH-NCI P30 CA12197.

\section{References}

1. Moertel CG: Chemotherapy for colorectal cancer. N Engl J Med 330: 1136-1142, 1994.

2. Peters GJ and Kohne CH: Fluoropyrimidines as antifolate drugs. In: Antifolate Drugs in Cancer Therapy. Jackman AL (ed). Humana Press Inc., pp101-145, 1999.

3. Peters GJ and Jansen G: Resistance to antimetabolites. In: Principles of Antineoplastic Drug Development and Pharmacology. Schilsky RL, Milano GA and Ratain MJ (eds). Marcel Dekker, Inc., New York, pp543-585, 1996.

4. Liu J, Skradis A, Kolar C, Kolath J, Anderson J, Lawson T, Talmadge $\mathrm{J}$ and Gmeiner WH: Increased cytotoxicity and decreased in vivo toxicity of FdUMP[10] relative to 5-FU. Nucleosides Nucleotides 18: 1789-1802, 1999.

5. Liu J, Kolar C, Lawson TA and Gmeiner WH: Targeted drug delivery to chemoresistant cells: folic acid derivatization of FdUMP [10] enhances cytotoxicity toward 5-FU-resistant human colorectal tumor cells. J Org Chem 66: 5655-5663, 2001.

6. Liu C, Willingham M, Liu J and Gmeiner WH: Efficacy and safety of FdUMP[10] in treatment of HT-29 human colon cancer xenografts. Int J Oncol 21: 303-308, 2002.

7. Peters GJ and Ackland SP: New antimetabolites in preclinical and clinical development. Exp Opin Invest Drugs 5: 637-679, 1996.

8. Bertino JR: Karnofsky memorial lecture. Ode to methotrexate. J Clin Oncol 11: 5-14, 1993.

9. Chu E, Callender MA, Farrell MP and Schmitz JC: Thymidylate synthase inhibitors as anticancer agents: from bench to bedside. Cancer Chemother Pharmacol 52 (Suppl. 1): S80-S89, 2003. 
10. Walling J: From methotrexate to pemetrexed and beyond. A review of the pharmacodynamic and clinical properties of antifolates. Invest New Drugs 24: 37-77, 2006.

11. Duch DS, Banks S, Dev IK, Dickerson SH, Ferone R, Heath LS, Humphreys J, Knick V, Pendergast W and Singer S: Biochemical and cellular pharmacology of 1843 U89, a novel benzoquinazoline inhibitor of thymidylate synthase. Cancer Res 53: 810-818, 1993

12. Rafi I, Taylor GA, Calvete JA, Boddy AV, Balmanno K, Bailey N, Lind M, Calvert AH, Webber S and Jackson RC: Clinical pharmacokinetic and pharmacodynamic studies with the nonclassical antifolate thymidylate synthase inhibitor 3,4-dihydro2-amino-6-methyl-4-oxo-5-(4-pyridylthio)-quinazolone dihydrochloride (AG337) given by 24-h continuous intravenous infusion. Clin Cancer Res 1: 1275-1284, 1995.

13. Bottomley A, Gaafa R, Manegold C, Burgers S, Coens C, Legrand C, Vincent M, Giaccone G and van Meerbeeck J: Short-term treatment-related symptoms and quality of life: results from an international randomized phase III study of cisplatin with or without raltitrexed in patients with malignant pleural mesothelioma: an EORTC Lung-Cancer Group and National Cancer Institute, Canada, Intergroup Study. J Clin Oncol 24: 1435-1442, 2006.

14. Ceresoli GL, Zucali PA, Favaretto AG, Grossi F, Bidoli P, Del Conte G, Ceribelli A, Bearz A, Morenghi E, Cavina R, Marangolo M, Parra HJ and Santoro A: Phase II study of pemetrexed plus carboplatin in malignant pleural mesothelioma. J Clin Oncol 24: 1443-1448, 2006.

15. Hochster H, Kettner E, Kroning H, Becker K, Lordick F, Ramanathan RK, Macdonald J, Hong S, John W and Schmoll HJ: Phase I/II dose-escalation study of pemetrexed plus irinotecan in patients with advanced colorectal cancer. Clin Colorectal Cancer 5: 257-262, 2005.

16. Maroun JA, Jonker D, Seymour L, Goel R, Vincent M, Kocha W, Cripps C, Fisher B, Lister D, Malpage A and Chiritescu G: A National Cancer Institute of Canada Clinical Trials Group Study - IND.135: phase I/II study of irinotecan (camptosar), oxaliplatin and raltitrexed (tomudex) (COT) in patients with advanced colorectal cancer. Eur J Cancer 42: 193-199, 2006.

17. Ayusawa D, Koyama H and Seno T: Resistance to methotrexate in thymidylate synthetase-deficient mutants of cultured mouse mammary tumor FM3A cells. Cancer Res 41: 1497-1501, 1981.

18. Keepers YP, Pizao PE, Peters GJ, van Ark-Otte J, Winograd B, and Pinedo HM: Comparison of the sulforhodamine B protein and tetrazolium (MTT) assays for in vitro chemosensitivity testing. Eur J Cancer 27: 897-900, 1991.

19. Peters GJ, Laurensse E, Leyva A, Lankelma J and Pinedo HM: Sensitivity of human, murine, and rat cells to 5-fluorouracil and 5'-deoxy-5-fluorouridine in relation to drug-metabolizing enzymes. Cancer Res 46: 20-28, 1986.

20. Rots MG, Pieters R, Kaspers GJ, van Zantwijk CH, Noordhuis P, Mauritz R, Veerman AJ, Jansen G and Peters GJ: Differential methotrexate resistance in childhood T- versus common/preBacute lymphoblastic leukemia can be measured by an in situ thymidylate synthase inhibition assay, but not by the MTT assay. Blood 93: 1067-1074, 1999.

21. Peters GJ, Laurensse E, Leyva A and Pinedo HM: Purine nucleosides as cell-specific modulators of 5-fluorouracil metabolism and cytotoxicity. Eur J Cancer Clin Oncol 23: 1869-1881, 1987.
22. Peters GJ, van Groeningen CJ, Laurensse EJ and Pinedo HM: Thymidylate synthase from untreated human colorectal cancer and colonic mucosa: enzyme activity and inhibition by 5 -fluoro2'-deoxy-uridine-5'-monophosphate. Eur J Cancer 27: 263-267, 1991.

23. Van Triest B, Pinedo HM, van Hensbergen Y, Smid K, Telleman F, Schoenmakers PS, van der Wilt CL, van Laar JA, Noordhuis P, Jansen G and Peters GJ: Thymidylate synthase level as the main predictive parameter for sensitivity to 5fluorouracil, but not for folate-based thymidylate synthase inhibitors, in 13 non-selected colon cancer cell lines. Clin Cancer Res 5: 643-654, 1999.

24. Gorlick R and Bertino JR: Drug resistance in colon cancer. Semin Oncol 26: 606-611, 1999

25. Mader RM, Muller M and Steger GG: Resistance to 5-fluorouracil. Gen Pharmacol 31: 661-666, 1998.

26. Rustum YM: Clinical implications of 5-FU modulation. Oncology 13: 22-25, 1999.

27. Shih C, Habeck LL, Mendelsohn LG, Chen VJ and Schultz RM: Multiple folate enzyme inhibition: mechanism of a novel pyrrolopyrimidine-based antifolate LY231514 (MTA). Adv Enzyme Regul 38: 135-152, 1998.

28. Shih C, Chen VJ, Gossett LS, Gates SB, MacKellar WC, Habeck LL, Shackelford KA, Mendelsohn LG, Soose DJ, Patel VF, Andis SL, Bewley JR, Rayl EA, Moroson BA, Beardsley GP, Kohler W, Ratnam M and Schultz RM: LY231514, a pyrrolo[2,3-d]pyrimidine-based antifolate that inhibits multiple folate-requiring enzymes. Cancer Res 57: 1116-1123, 1997.

29. Spears CP, Gustavsson BG, Berne M, Frosing R, Bernstein L and Hayes AA: Mechanisms of innate resistance to thymidylate synthase inhibition after 5-fluorouracil. Cancer Res 48: 5894-5900, 1988.

30. Ford HE, Mitchell F, Cunningham D, Farrugia DC, Hill ME, Rees C, Calvert AH, Judson IR and Jackman AL: Patterns of elevation of plasma 2'-deoxyuridine, a surrogate marker of thymidylate synthase (TS) inhibition, after administration of two different schedules of 5-fluorouracil and the specific TS inhibitors raltitrexed (Tomudex) and ZD9331. Clin Cancer Res 8: 103-109, 2002.

31. Forsthoefel AM, Pena MM, Xing YY, Rafique $Z$ and Berger FG: Structural determinants for the intracellular degradation of human thymidylate synthase. Biochemistry 43: 1972-1979, 2004.

32. Jarmula A, Cieplak P, Les A and Rode W: Relative free energies of binding to thymidylate synthase of 2- and/or 4-thio and/or 5-fluoro analogues of dUMP. J Comput Aided Mol Des 17: 699-710, 2003.

33. Myers CE, Young RC and Chabner BA: Biochemical determinants of 5-fluorouracil response in vivo. The role of deoxyuridylate pool expansion. J Clin Invest 56: 1231-1238, 1975.

34. Peters GJ, Backus HH, Freemantle S, Van Triest B, CodacciPisanelli G, van der Wilt CL, Smid K, Lunec J, Calvert AH, Marsh S, McLeod HL, Bloemena E, Meijer S, Jansen G, van Groeningen CJ and Pinedo HM: Induction of thymidylate synthase as a 5-fluorouracil resistance mechanism. Biochim Biophys Acta 1587: 194-205, 2002. 